\title{
Sequential patterns of students' drawing in constructing scientific explanations: Focusing on the interplay among three levels of pictorial representation
}

Park, J. ; Chang, J. ; Tang, K.S. ; Treagust, D.F. and Won, M.

\begin{abstract}
The purpose of this study is to investigate the process of students' construction of scientific explanations through drawing explanatory diagrams. For this, we observed fifth and sixth graders' drawing processes in a gifted science class involving learning physics concepts in mechanics. The analysis was carried out on three pictorial representational levels: sensory (e.g., observed materials), unseen substance (e.g., molecules) and unseen non-substance (e.g., forces). We found that there were five patterns of interplay depending on the sequential path through the pictorial representational levels. All students began drawing explanatory diagrams from the sensory level as the first step and then constructed explanations using the unseen levels based on the interplay among different levels. In the process of forming meaningful relationships among the three levels of representation, students focused on a specific phenomenon through drawing at a sensory level and extended their making sense of the phenomenon from what happened to why it happened. Based on these findings, we suggest how teachers can use the interplay among the different pictorial representational levels to guide students in generating scientific explanations through drawing.
\end{abstract}

Keywords: student-generated drawing, scientific explanations, pictorial representations, interplay 


\section{Introduction}

Students can improve their scientific understanding through constructing scientific explanations with multiple representations (Tytler \& Prain, 2010) by making sense of a phenomenon based on scientific theories and models known to them (Berland \& Reiser, 2009). In light of this advantage, many discussions have been reported in the area of generating scientific explanations using various external representations (e.g., Forbes, Lange, Möller, Biggers, Laux, \& Zangori, 2014; Authors, 2016), such as text, diagrams, gestures, graphs and mathematical representations. In a further, many studies have examined types of representation in terms of variety, similarities, differences, affordances, and features. Since each external representation has its intrinsic features and certain roles, in order to investigate each representation's effective strategies, some studies have focused on multimodal representation (e.g., Yeo \& Gilbert, 2014), which is related to the combination of modes (e.g., speech, images, gestures) in scientific concepts. On the other hand, other studies have been more interested in multiple representations (e.g., Authors, 2017), which are related to the practice of rerepresenting one external representation using another representation (Authors, 2014). It is common and effective for two or more forms of external representation be provided or generated in the science learning environment.

To reveal the features of each external representation, it is necessary to examine how the external representation affects the information utilised and what is perceived and how reasoning proceeds when drawing the representation (Zhang, 1997). If we focus on the specific representation to be examined, we can uncover its intrinsic features, especially as students construct their explanations. In the case of this study, we focused on student-generated drawing, an area which has grown in attention during the last two decades. Drawing has various benefits in learning science in terms of its relationship with reasoning, communicating, understanding, and assessment (Ainsworth, Prain, \& Tytler, 2011; Prain, Tytler, \& Peterson, 
2009; Quillin \& Thomas, 2015). However, previous studies on drawing diagrams, have been more focused on the product in terms of the role of or the effectiveness with the other important components in science learning such as improving students' conceptual understanding (e.g., Hsieh \& Tsai 2017; Tippett, 2016). Although the process of students' constructing explanations with their diagrams have been investigated in a few cases, these studies focus more on multimodal integration that involves a wide range of representations besides drawing (e.g., Kress, Jewitt, Ogborn, \& Tsatsarelis, 2001; Authors, 2014; Yeo \& Gilbert, 2017). Few studies have discussed the process of drawing itself which contains the visual components in constructing explanations.

How then do we explore the process of drawing? In order to reveal this process, we focused on the sequence in which students draw diagrams in terms of multiple representational levels (Johnstone, 1982), which is the typical and efficient classification to understand students' understanding from their visual representations. In the case of drawings, the representational level can be specifically pictorial. One concern raised from these studies is the importance of helping students make appropriate links between different representational levels (Authors, 2009). In the students' drawing process, the levels of representations may emerge in their drawn diagrams and these levels may interact with each other to provide a coherent explanation. For example, we know from the history of science that Michael Faraday created his electromagnetic induction theory through the integration and interplay among different levels of various representations (Gooding, 2006). Likewise, this interplay of levels could also emerge in the sequential process of students' constructing explanations: The process would emerge as the sequential pattern in relation to the interplay among the levels of representation. Therefore, to investigate this process of drawing further, the research questions that guide this study are as follows: 
(1) What sequential patterns emerged in students' drawing in terms of different levels of pictorial representation?

(2) What are roles of the levels of pictorial representation in constructing explanations?

\section{Theoretical background}

\section{Overview of drawing diagrams}

Drawing diagrams have many advantages in learning science. For example, drawing diagrams have been seen as an effective strategy during the planning stage where divergent thinking is needed is most needed in solving physics problems (Maries \& Singh, 2017). This heuristic advantage might stem from a feature of the drawing itself by spreading out many things on a two-dimensional surface simultaneously (Larkin \& Simon, 1987). If we regard this process as a heuristic process, the drawings involving preliminary ideas can serve as seeds for development of future ideas.

In the last decade, there has been more interest in drawing diagrams as a science learning strategy. For example, Ainsworth et al. (2011) emphasised drawing in learning science as an integral process in scientific thinking to enhance engagement, deepen understanding of concepts, and represent and communicate with others. Furthermore, encouraging results in the understanding scientific concepts through drawing diagrams have been reported (e.g., Preston, 2016).

On the other hand, external representations contain different information.

Diagrammatic or pictorial representations have locational information on a plane, and this information is displayed implicitly, in contrast to sequential representation, which shows information sequentially as in propositions (Larkin \& Simon, 1987). Because different forms of external representation have their own intrinsic information, they have complementary relationships with other external representations (Van Meter \& Garner, 2005). For example, the 
processes of explaining to someone how to arrive somewhere with or without using a map are very different processes. The advantages and features involved in drawing a scientific diagram emerge only in the creation of visual representations.

\section{Three levels of pictorial representation in learning physics at a qualitative understanding stage}

The theory of multiple representational levels has played a central role in the research field of multiple representations (Talanquer, 2011). Based on this idea, many studies have broadened our understanding of how students visualise and learn scientific concepts as well as how students' learning can be facilitated in terms of integrating various levels of representation. In order to represent scientific ideas in science education, various types of representation have been conceptualised having two to four levels. Authors (2009) summarised previous research and described three types of representations: phenomenological (macro level), model (submicro level) and symbolic (symbolic level). Although these three levels were developed when focusing on chemistry education, they have been widely used in science education (e.g., Yeo \& Gilbert, 2014).

These types of representations or classifications fit well with learning chemistry and subjects like biology as shown in many studies. However, there is some disagreement in representing non-substances in learning physics by a novice learner. The main purpose of the typical classification is to develop a coherent understanding of the triple relationship of these levels (Authors, 2009). This means that understanding and representing the idea of the same object on all three levels are the goals for better understanding; this process involves both qualitative content (which refers to sub-micro levels) and quantitative content (which refers to the symbolic level; Bucat \& Mocerino, 2009). The symbolic level of these types consists of social conventions that are hard to spontaneously understand and students often have difficulty 
understanding the complex conventions (Marais \& Jordaan, 2000). For novice learners who are more interested in qualitative understanding, we should focus more on the macro and submicro levels. In particular, considering the approach to learning physics that deeper understanding comes in progressing from qualitative to quantitative content (Uhden, Karam, Pietrocola \& Pospiech, 2011), this focus is important to learning physics in primary and middle schools when students are novice learners. On the other hand, these three levels of classification are more related to substances, which are essential and crucial in chemistry education. When learning physics, non-substances are also as important as substances in understanding physics concepts. For example, force, which is a non-substance, is the interaction between substances and is the core concept for understanding the mechanism of a phenomenon. Although we can represent force on the symbolic level, it does not fit well with the triple relationship that can be seen when learning chemistry. The relationship between the three levels in learning physics in a qualitative way is thus different from the typical classification in chemistry education. Considering these aspects, we developed three different levels of pictorial representation when learning physics in a qualitative way as shown in Figure 1.

The first level is the sensory (SS) level, which includes what we can sense as substances. This level includes both the substance itself and any movement of the substance that we can observe or feel. If we use an arrow to represent the movement of a ball, this is the SS level. The second level is unseen substance (US) level, which includes substances that cannot be seen unaided but can only be observed such as with an electron microscope. This level includes unseen particles such as water molecules and the movement of particles. If we use an arrow to represent the movement of air particles, this is the US level. The last level is the unseen non-substance (UN) level, which includes what we cannot see even when magnified. This level includes non-substances such as force, which is an interaction between substances. These are summarised as follows: 
(1) Sensory: What we can see, such as materials; representations include arrows showing movement such as that of a ball

(2) Unseen substance: What we cannot see unaided such as particles; representations include arrows showing movement, such as that of particles

(3) Unseen non-substance: What we cannot see even when magnified, such as force; representations include arrows for gravity on a falling ball

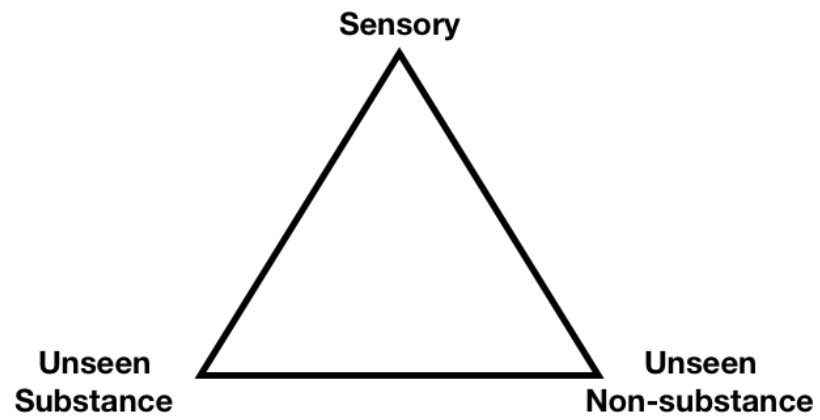

Figure 1. Three levels of pictorial representation in learning physics at a qualitative understanding stage

Mathematical representations play a crucial role in learning physics in helping to achieve a deeper understanding of physical phenomena (Redish \& Kuo, 2015). However, this role in further learning does not mean that mathematical representation and reasoning should be dealt with at the beginning because for students, as novice learners, an appropriate approach is to present qualitative understanding first. In this sense, our classification is appropriate for novice learners. For levels of further learning within the representation of ideas, we should consider the mathematical symbols and other elements of ontological categorisation.

\section{Types of scientific explanations}

Scientific explanations have long played a key role in science education: Students in the 
science classroom are often asked to construct scientific explanations in order to encourage scientific understanding (Braaten \& Windschitl, 2011). Six types of explanations are proposed by Gilbert, Boulter, \& Rutherford's (2000) study; however, causal, interpretive and descriptive explanations are the most frequently dealt with in the science classroom. Students' construction of causal explanations has been recognised and favoured as a more desirable state in the science classroom than the construction of descriptive explanations (Author, 2016; Yeo \& Gilbert, 2014). Students' construction of interpretive explanations has also been regarded as a successful product in mathematical representations (Yeo \& Gilbert, 2017). Although constructing both causal and interpretive explanations have received most attention by researchers, descriptive explanations have their own role, especially in primary school science (Gilbert et al., 2000). Consequently, this study focused on these types of explanations and summarised how they are related to the kind of questions shown in Table 1.

Table 1. Types of explanation (Gilbert et al., 2000)

\begin{tabular}{cc}
\hline Types of explanation & Question answered \\
\hline Descriptive & What are the properties of a phenomenon? \\
\hline Interpretive & What models can be used to think about the phenomenon? \\
\hline Causal & Why does the phenomenon behave as it does? \\
\hline
\end{tabular}

\section{Research Method}

\section{Participants and context of the study}

Fifteen fifth and sixth grade students in a gifted science class in Australia participated in this study. They were observed during one 120-minute lesson per week for five weeks during which the lesson topics were the nature of matter and pressure of water and air. The lessons were planned following the Thinking Frames Approach (TFA; Newberry \& Gilbert, 2007). 
This approach consists of five steps: Posing a question for students to make predictions as a group, doing a hands-on activity to observe a scientific phenomenon, sharing ideas as the whole class, visualising explanations with diagrams, and writing written explanations. The second and third steps of this approach require group activities, so a four-group setting was arranged (see Table 2). Students were asked to complete a worksheet involving drawing an explanatory diagram and writing an explanation of the main question (see the electronic resources: https://goo.gl/rQVBWK). The topics were selected over the course of meetings with all authors with the prime considerations being the ease of using visuals to illustrate concepts and the backgrounds of the participants. For example, the concept of air pressure was considered a good topic for students to draw. Students tend to be familiar with this concept in everyday life, and visualising this concept using drawings can be helpful in understanding this concept. This was the first time the students had been asked to draw diagrams in a science classroom.

Table 2. Group setting

\begin{tabular}{ccccc}
\hline & Group 1 & Group 2 & Group 3 & Group 4 \\
\hline $\begin{array}{c}\text { Students' } \\
\text { pseudonym }\end{array}$ & G1S1, G1S2, G1S3, & G2S1, G2S2, G2S3, & G3S1, G3S2, G3S3 & G4S1, G4S2, G4S3, \\
\hline Gender & 2 Boys, 2 Girls & 3 Boys, 1 Girl & 3 Boys & G4S4 \\
\hline
\end{tabular}

\section{Data collection}

Following approval of all formal ethics procedures, the data were collected by three means: researcher's field notes of their participant-observations (including their questions to students; video and audio recordings; and the drawings completed by students. The first three researchers, R1, R2 and R3, observed and participated in the lessons by questioning students to reflect on their thinking and helping them to construct explanations. Asking students questions 
is a necessary process in understanding students' intentions to draw and their thoughts. The purpose and context of these questions may be similar to the teaching experiment suggested by Steffe (1991) because we wanted to learn about students' approaches and reasoning when they make the drawings. Even though the purpose of these questions is to help facilitate students' thinking, these questions may affect their development. In order to minimise these interventions, the questions asked by the researchers, such as 'What is the meaning of this arrow?' and 'Can you tell me your plan for drawing?' focused on exploring students' thinking rather than providing direct information for drawing. In addition, when students had difficulties, the researchers first asked students specific, guiding questions such as 'Why does this solid have definite shape and volume?' rather than asking a more general question such as 'Why it happened?' so that they could develop their explanations step by step. Only when students could not develop their explanations in spite of these 'why' questions did the researchers suggest that the students think in terms of particles. These kinds of questions did not directly request students to make specific types of representations but rather prompted them to think about the representations that were required for the explanations. Before the students' drawing activity, they had done experiments and discussed their explanations with their peers and the teacher in their small groups and then with the whole classroom. The questions asked by the researcher were thus not their first prompts. Consequently, the data were thoroughly analysed with the discussions to show how this intervention may have affected students' sequential patterns. The field notes written by the three researchers when observing the lessons and the dialogues with students were also collected. The lessons were recorded using cameras and audio recorders in each group, including the teacher's contributions to the discussions. In particular, in order to show the processes of students' drawings, cameras were focused on students' drawings. Sixty-seven worksheets completed by students were collected. 


\section{Data analysis}

Analytic framework

To analyse the data from this study, we developed the analytic framework shown in Table 3 that involves verbal representations, levels of pictorial representation and types of explanation. The verbal representation provides the data used to infer students' thinking in order to analyse the pictorial representation. In the process of generating the pictorial representation, a verbal representation plays a crucial role in organising the conceptual elements and serves as a foundation (Van Meter \& Garner, 2005). In addition, drawings can play a role that is complementary to verbal representation (Ainsworth et al., 2011) when students construct scientific explanations. This means that we can use the verbal representation to analyse each process of constructing a pictorial representation. Thus, the verbal representation section needs to be presented with the pictorial representation even though this is not the main object of analysis. In the pictorial representation, the level of each drawing was analysed according to our model as shown in Figure 1. In terms of type of explanation, two out of the three common types (Gilbert et al., 2000) were relevant to this study: descriptive and causal explanations. Interpretive explanation, which is related to mathematical and quantitative reasoning, rarely emerged in drawing diagrams with these primary school students.

Table 3. Analytic framework

\begin{tabular}{|c|c|c|c|c|c|c|}
\hline \multirow{2}{*}{$\begin{array}{c}\text { Focus of } \\
\text { phenomenon } \\
\text { (segment) }\end{array}$} & \multirow{2}{*}{$\begin{array}{l}\text { Verbal } \\
\text { representation }\end{array}$} & \multicolumn{4}{|c|}{ Pictorial representation } & \multirow{2}{*}{$\begin{array}{c}\text { Type of } \\
\text { explanation }\end{array}$} \\
\hline & & Time & Turn & Drawing & $\begin{array}{l}\text { Level of } \\
\text { representation }\end{array}$ & \\
\hline Focus 1 & & & 1 & & Sensory (SS) & $\begin{array}{c}\text { Descriptive } \\
\text { explanation } \\
\text { (DE) }\end{array}$ \\
\hline Focus 2 & & & 2 & & $\begin{array}{c}\text { Unseen substance } \\
\text { (US) }\end{array}$ & $\begin{array}{c}\text { Causal } \\
\text { explanation (CE) }\end{array}$ \\
\hline
\end{tabular}




\section{Processes of analysis}

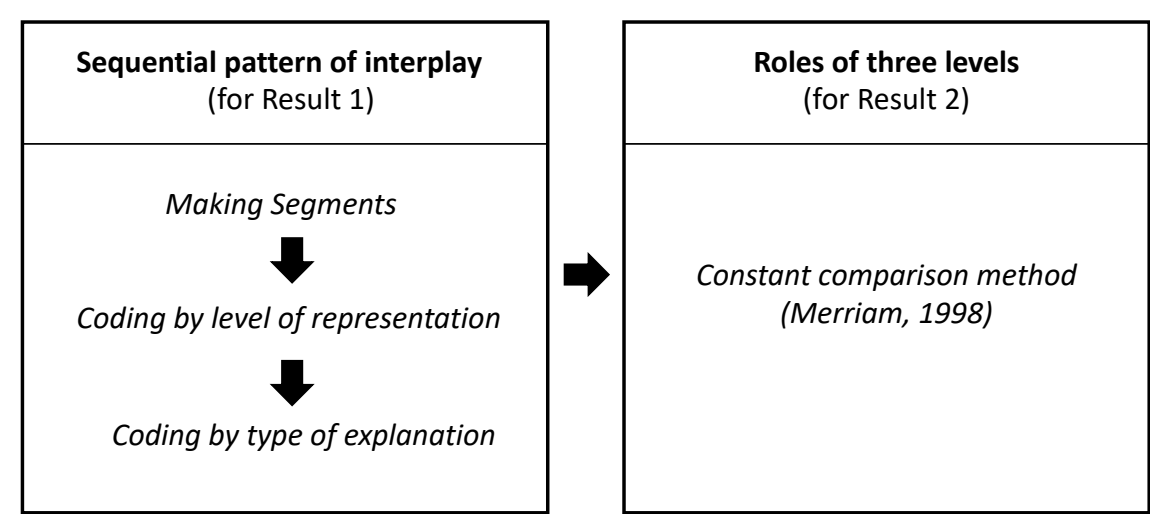

Figure 2. Processes of analysis

The analysis consisted of two parts as shown in Figure 2. For the first part, we analysed the sequential patterns of interplay among the pictorial representational levels in the students' drawings. For the second part, we analysed the roles of the three levels in that process.

In the first part of the analysis, we made segments of each drawing in order to answer the main question, with each segment being a unit of analysis and focusing on one phenomenon to be represented in the drawing. A segment is a semantic unit of discourse that deals with one theme or topic (Van Dijk, 1981). Drawing was analysed by breaking a whole drawing into its smaller parts by identifying clusters of drawings that are separated from one another (Authors, 2014). For example, in the first lesson there are three separated targets (solids, liquids and gases) in a large drawing which enabled us to break it down into three smaller drawings as the units of analysis. Each segment was then divided into small turns that showed specific concepts such as an arrow and circle to represent the movement of the particle; a key was given to show the meanings of the symbols. The keys and descriptions in the drawings were regarded as verbal explanations. For each segment, we then analysed the 
drawings following the analytic framework shown in Table 3 by classifying every smaller turn according to its representational level (SS, US or UN) and type of explanation (descriptive explanation $[\mathrm{DE}]$ or causal explanation $[\mathrm{CE}])$.

Based on the focus of sequential development of students' drawings, five representational patterns were established. These sequential patterns were numbered by the number of levels that emerged and in what order they emerged. Each pattern was also named to represent the features of sequential development at that level. In the process of determining the explanation type, we considered the cause-and-effect relationships when students used terms such as 'reason', 'because' and 'due to'. The segments were analysed individually by the first and second authors and their inter-rater reliability score was $94.5 \%$. Examples of this analysis are illustrated in the results section. The final stages of the drawings that were used in this study are presented in electronic resources (see https://goo.gl/rQVBWK) in order to provide more clear and whole images.

For the second part of the analysis, using the corpus of data that included the results from the first analysis, we used the constant comparison method (Merriam, 1998) and focused on the roles of the three levels of pictorial representation in constructing explanations. In this analysis, we focused both on the smaller parts of the drawings and on the entire drawings in order to understand the students' thinking in the drawing process. We constructed categories and then sorted the categories and the data. We then named the categories to represent the main feature of each category. For drawings at the SS level, for most students, drawing a specific phenomenon involved further development into the other two levels. Representative examples that showed different developmental trajectory are illustrated in the Results section. On the other hand, drawings at the unseen US and UN levels did not always involve causal explanations. However, there were exceptions such as drawing collisions of air particles prompting drawing pressure based on the effect of these collisions. Thus, this role of drawing 
the unseen levels was analysed and representative examples were shown. We followed this procedure inductively and comparatively in doing the analysis to arrive at a consensus of the analysis.

\section{Results}

\section{Response to research question 1: Five sequential patterns of interplay among different levels in students' drawings}

We found five sequential patterns of interplay in terms of how the representational levels (e.g., SS, US, UN) progressed in the students' drawings. A summary of the sequential patterns and the corresponding number of group drawings from each lesson is shown in Table 4. All patterns began at the SS level, which can be observed by the learners. Pattern 1 showed only the SS level of the pictorial representation. Patterns 2-1 and 2-2 began at the SS level and interacted with and progressed to either the US or UN level. Patterns 3-1 and 3-2 began at the SS level and interacted with and progressed to both the US and UN levels. Pattern 3 depicts all levels of pictorial representation and indicates the strongest possible explanation when constructing a pictorial explanation. We illustrate each pattern with a representative example from our data.

Table 4. Summary of patterns with the corresponding number of group drawings from each lesson

\begin{tabular}{cccccccc}
\hline & Levels & Lesson 1 & Lesson 2 & Lesson 3 & Lesson 4 & Lesson 5 & Sum \\
\hline Pattern 1 & SS & 1 & 1 & 0 & 0 & 0 & 2 \\
\hline Pattern 2-1 & SS-US & 4 & 1 & 9 & 9 & 7 & 30 \\
\hline Pattern 2-2 & SS-UN & 1 & 2 & 1 & 0 & 0 & 4 \\
\hline Pattern 3-1 & SS-US-UN & 3 & 6 & 3 & 3 & 5 & 20 \\
\hline Pattern 3-2 & SS-UN-US & 4 & 5 & 1 & 0 & 1 & 11 \\
\hline Total & & 13 & 15 & 14 & 12 & 13 & 67
\end{tabular}

Note: In total, 67 diagrams from the five lessons were classified into the five patterns. 
Pattern 1 (only SS): Just drawing what they observed

Students who followed Pattern 1 showed only the sensory level and did not include the other unseen levels of representation. The students who followed this pattern drew what they could see and sense at the SS level as a descriptive explanation even though the teacher and researchers encouraged them many times to draw unseen things such as asking them to think in terms of the particles. We thus inferred that they had insufficient understanding on why the scientific phenomena happened, how to draw scientific diagrams, or the importance of drawing at the US and UN levels. Two students followed this pattern in the first lesson, one student followed it in the second lesson and there was no student in the subsequent lessons. This observation may be the result of students starting to understand the microworld view of matter in relation to the concepts of air pressure and attraction between particles during the first and second lessons.

For example, in Lesson 1, students were asked to answer the question: If we tilt three bottles, one containing solids, one containing liquids and one containing gases, what happens in each bottle in terms of particles? A Lego brick, pure water and smoke from an incense were used in the experiment to represent the solids, the liquids and gases, respectively. We can see an example of Pattern 1 in Table 5. A student, G3S3, depicted what he could observe of the phenomenon in detail but he did not draw any further explanations in response to the researcher's questions such as those shown in Line 1. In Line 2 of the verbal representation, he only described the phenomenon in terms of the flexibility and hardness of gas and solid when he was prompted to explain why. If he knew the cause-and-effect of this phenomenon, he should be able to draw the unseen mechanism but did not do so. At the same time, considering that most students who drew according to the other patterns began with this sensory level, this pattern is a basic step in the progress of creating an explanatory diagram. 
Table 5. G3S3's drawing in Lesson 1

\begin{tabular}{|c|c|c|c|c|c|c|}
\hline \multirow{2}{*}{ Focus } & \multirow{2}{*}{ Verbal representation } & \multicolumn{4}{|c|}{ Pictorial representation } & \multirow{2}{*}{ Type } \\
\hline & & Time & Turn & Drawing & Level & \\
\hline \multirow{6}{*}{$\begin{array}{c}\text { Water } \\
\text { movem } \\
\text { ent }\end{array}$} & (Group 3, 01:37:25) & & \multirow{6}{*}{1} & & \multirow{6}{*}{ SS } & \multirow{6}{*}{$\mathrm{DE}$} \\
\hline & $1 \mathrm{R} 1$ : What are differences between & & & & & \\
\hline & solids, liquids and gases? Why gas & 01:32: & & & & \\
\hline & particles can go around freely? & 16 & & & & \\
\hline & 2 G3S3: It [gas] is flexible ... [The solids & & & & & \\
\hline & is] The hard one... & & & & & \\
\hline
\end{tabular}

Pattern 2-1 (SS-US): Drawing what is going on in the phenomena descriptively

Pattern 2-1 involves students representing their ideas to show the phenomenon at the SS and US level, but not the UN level which shows the relationships between the substances. Students who followed this sequential pattern first drew what can be seen and then drew what cannot be seen unaided. Although at first students had difficulty drawing or representing particles that cannot be seen, they were able to draw at the US level later with the help of the teacher and the researchers emphasising the existence of particles. We can see an example of this pattern in Table 6.

To answer the question in Lesson 1 which is the same as pattern 1, G4S1 drew what he could see at the SS level first and then added the particles that are at the US level to his drawing. As shown in Table 6, this student had drawn only the SS level based on his observation of the position of Lego brick (Line 5 in Table 6), which was noticed by the members of Group 1. The teacher and researchers made many attempts, for example, by questioning, to encourage the student to think about why a phenomenon happened in terms of particles (Lines 6 and 8), which helped him to describe how the particles are represented at the US level within the relationship between the SS and US levels. Nevertheless, his drawing did not answer the 'why' questions, because the drawing did not make a causal explanation about why the bricks keep their shape. Although the student in this pattern was questioned in terms 
of thinking using particles and 'why' questions, he only drew particles when answering the main question. Considering that this drawing was his first opportunity to use particles in his drawing, this was a challenge for him so he could not further develop the explanation in terms of drawing at the UN level or making a causal explanation. Thus, we can infer that the students who followed Pattern 2-1 understood what happened at both the SS and US levels but did not understand why it happened.

Table 6. G4S1's drawing in Lesson 1

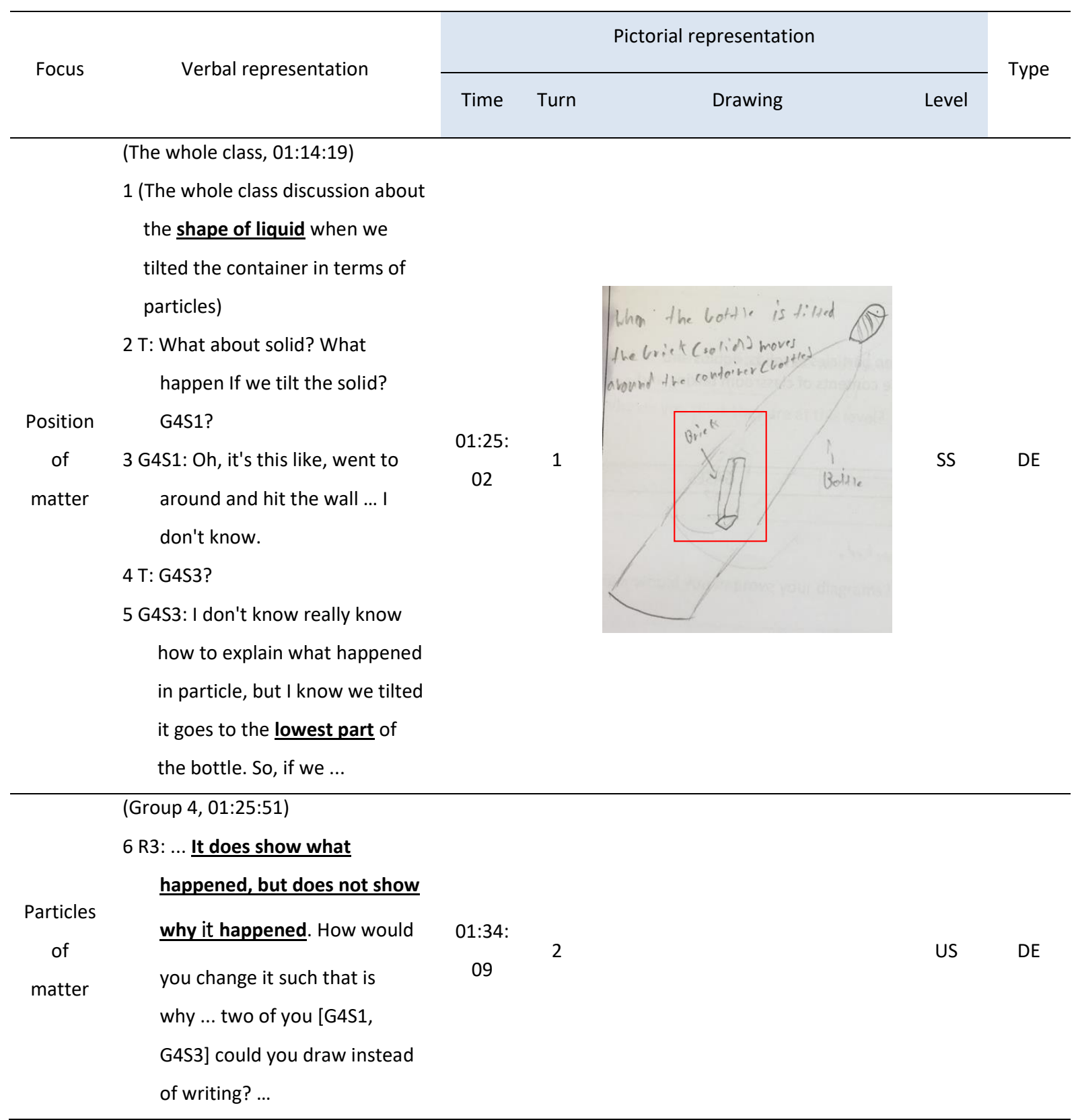




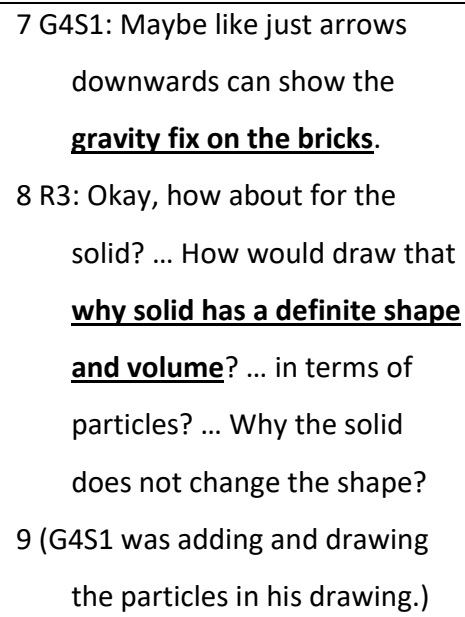

Pattern 2-2 (SS-UN): Drawing what they observed and its mechanism

Pattern 2-2 involved drawing the SS level first and then drawing the UN level. In this pattern, students drew the mechanism of the phenomenon using the scientific concepts at the UN level after drawing what they could observe at the SS level. Although it is difficult to confirm whether the students who followed this pattern knew why the phenomenon occurred or not, their drawings shows that these students represented the main concept to make sense of the scientific phenomenon based on the interplay between the SS and UN levels. The case in Table 7 shows an example of this pattern.

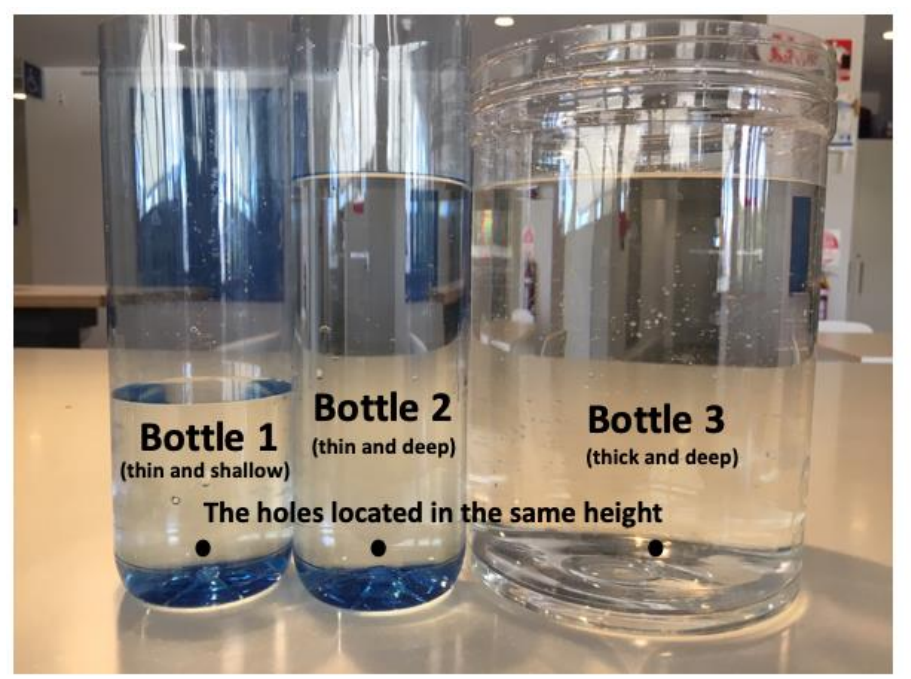

The same size of bottles: Bottles 1 and 2 The same depth of water: Bottles 2 and 3

Figure 3. Three bottles of water used in Lesson 2 
The question in Lesson 2 was "How are the length of the jets of water different depending on the size of the bottle and the water depth? Why?" Three bottles (see Figure 3) were used to compare the length of water jets. After observing water jetting out from the bottom of three different bottles, G3S2 began his explaining by drawing at the SS level depicting the difference of the length of water (Turn 1). He then drew arrows at the UN level in Turn 2 to represent the differences in water pressure between Bottles 2 and 3, with the longer arrows representing more pressure and shorter arrows representing less pressure in Bottle 1 (Turn 2), thus showing that he knew why the length of the water jets coming from Bottles 2 and 3 were longer than Bottle 1's. As shown in Figure 4, what he wrote before his drawing also indicates that he already knew why this occurred in terms of the relationship between water pressure and depth (height of the water). We thus can say he generated a causal explanation with his drawing based on his understanding of the phenomenon. In addition, in order to answer R1's question about why the water pressure was the same in Bottles 2 and 3 even though the amount of water was different, he drew a line at the UN level to represent the reason the water pressure in Bottles 2 and 3 was the same (Turn 3), making the reason clearer in the drawing by elaborating the water pressure concept. We interpreted that the students who followed Pattern 2-2 generated a causal explanation based on their understanding of what happened and why it happened.

Table 7. G3S2's drawing in Lesson 2

\begin{tabular}{|c|c|c|c|c|c|c|}
\hline \multirow{2}{*}{ Focus } & \multirow{2}{*}{ Verbal representation } & \multicolumn{4}{|c|}{ Pictorial representation } & \multirow{2}{*}{ Type } \\
\hline & & Time & Turn & Drawing & Level & \\
\hline $\begin{array}{l}\text { Length of } \\
\text { water jet }\end{array}$ & - & $\begin{array}{c}01: 25: \\
00\end{array}$ & 1 & - & SS & $\mathrm{DE}$ \\
\hline
\end{tabular}




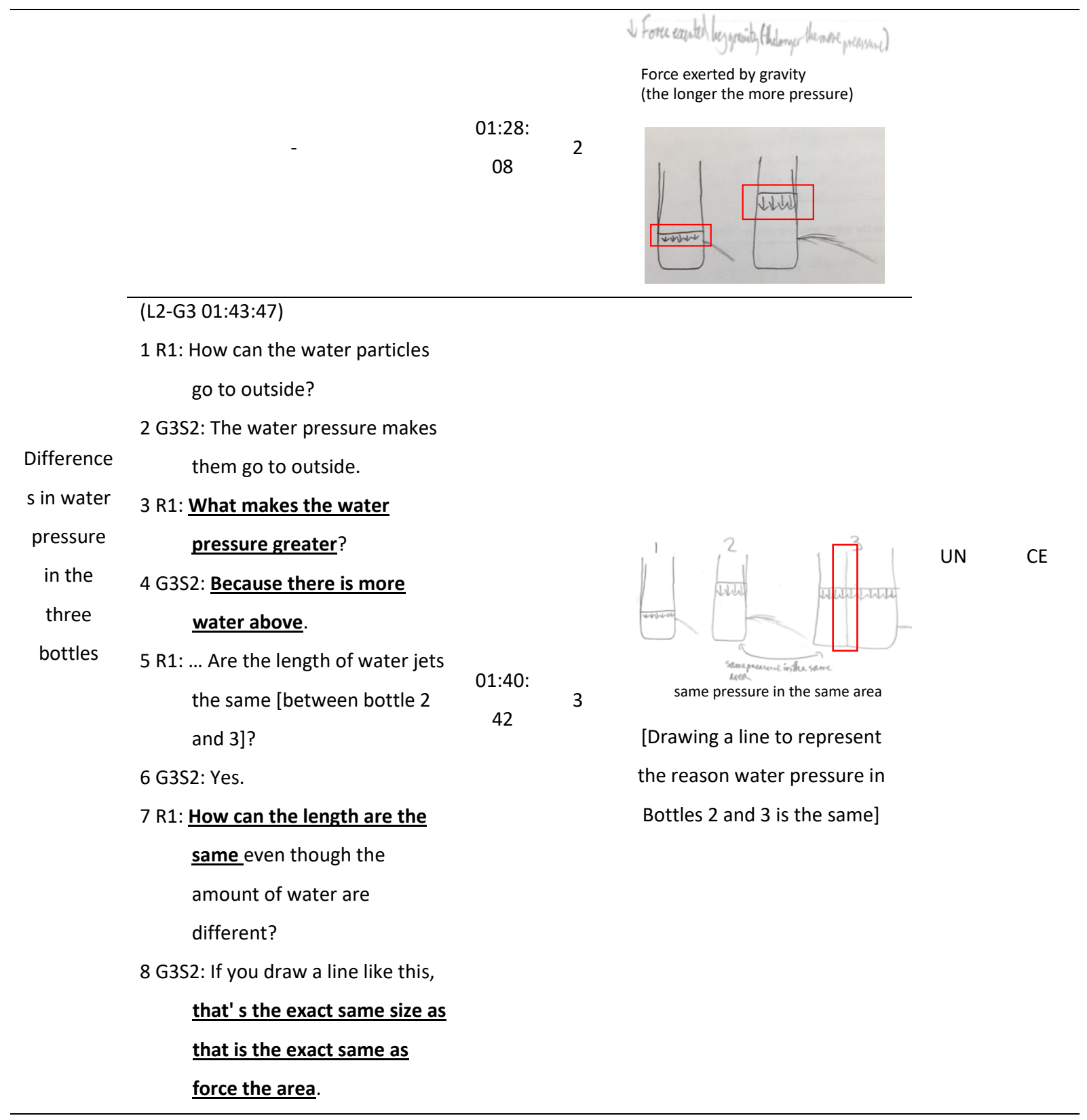

As you swim deeper, how does the water pressure change? Why?

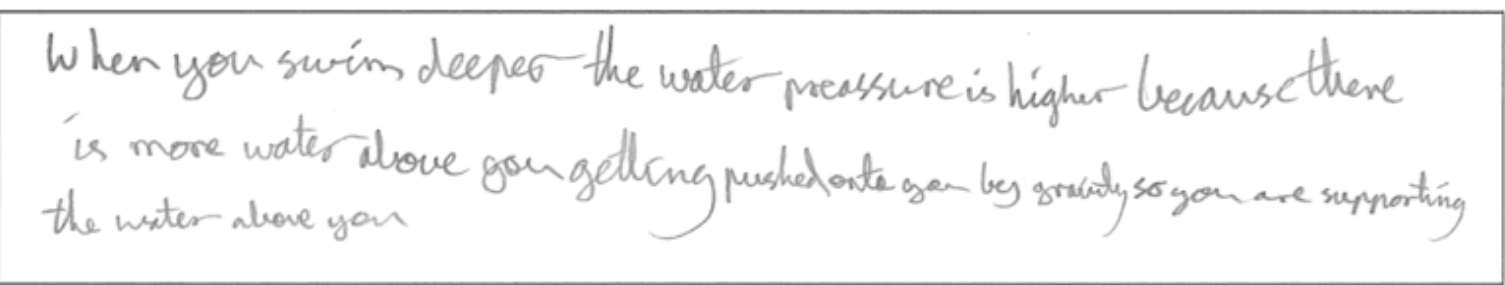

Text: 'When you swim deeper the water pressure is higher because there is more water above you getting pushed onto you by gravity, so you are supporting the water above you.'

Figure 4. G3S2's written explanation about the water pressure 
Pattern 3-1 (SS-US-UN): Drawing the scientific phenomenon descriptively and finding the mechanism

Pattern 3-1 involved students drawing an explanatory diagram showing all three levels of pictorial representation. These students progressed the furthest, forming a relationship through the interplay among three levels. When beginning to draw, they focused on describing the phenomenon at both the SS and US levels. In the final stage, they used the UN level to represent why the phenomenon happened using physics concepts and returned to the other representational levels in order to consolidate their explanations.

Table 4 shows that this pattern had the second highest occurrence (20 occasions) in students' drawings. We can infer that this pattern shows there was a development and improvement from Pattern 2-1, which is from the SS level to the US level. The following example shows this interpretation.

In Lesson 4, students observed an experiment where an egg was placed on the top of a glass bottle which was heated and cooled within a big bowl filled by boiled and iced water respectively. They were then asked to explain: "What happened to the egg and the inside and outside of the bottle, and why?" During Turn 3 in the drawing in Table 8, G1S4 drew lines on both the top and bottom of the egg in order to show the difference in pressure. This was the main cause of the egg going into the bottle even though the size of the hole was smaller than the diameter of the egg. Her understanding of this principle is shown in her verbal representation (Line 4 in Table 8) and written explanation (Figure 5). She may have developed this idea through drawing the particles when she was asked to think about the state of particles related to such things as speed and energy. Eliciting this type of interplay among the representational levels helped create relationships between them when constructing explanations. Consequently, this process of descriptive drawing at the SS and US levels 
prompted the idea about the mechanism at the UN level as an interpretive concept, thus consolidating their relationships.

Table 8. G1S4's drawing in Lesson 4

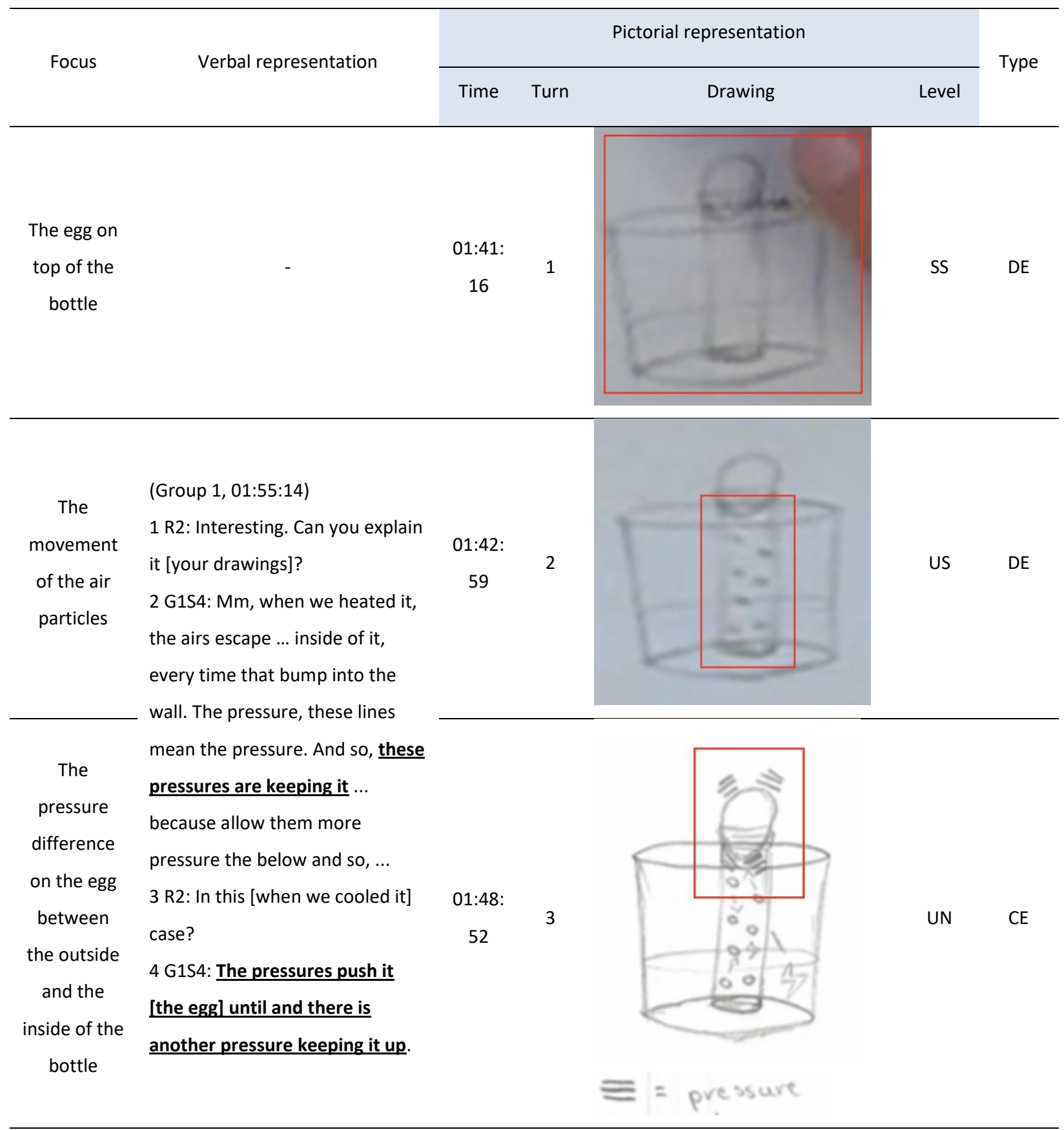




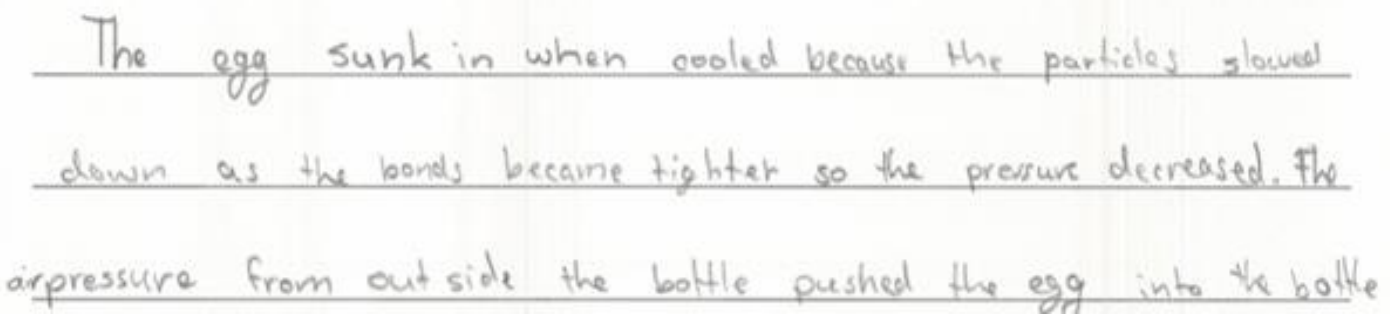

Text: 'The egg sunk in when cooled because the particles slowed down as the bonds became tighter so the pressure decreased. The air pressure from outside the bottle pushed the egg into the bottle.'

Figure 5. A part of G1S4's written explanation

Pattern 3-2 (SS-UN-US): Drawing what is observed and its mechanism within the nature of the matter

Pattern 3-2 involved students drawing an explanatory diagram based on the interplay among all three levels of pictorial representation. Students who followed this pattern first drew the result of the experiment and equipment at the SS level and soon drew the UN level as a main factor to make sense of the phenomenon. They finished their drawings by showing particles, which is the nature of matter, in order to further explain the concept that was shown at the UN level. We can surmise that this pattern may have developed from Pattern 2-2, from the SS to the UN level, through making deeper relationships among the three levels. An example of this pattern is shown in Table 9.

In the drawing of Lesson 2 shown in Table 9, G4S3 drew the length of water jets first and then drew the symbol that he created himself to represent pressure, which is the main concept necessary to interpret the phenomenon. He finished by drawing the particles at the US level in order to explain the origin of water pressure (Lines 4 and 6). His written explanation in Figure 6 shows that from the beginning he knew that the reason the lengths of the water jets were different was due to differences in water pressure. This text also shows that he understood that the water pressure is affected by gravity on each particle. Thus, he was able to draw the water pressure after drawing the main result of the experiment that he had seen. He then drew 
the water particles to represent where the water pressure comes from. This idea, which is a causal explanation, further strengthened the explanation.

Table 9. G4S3's drawing in Lesson 2

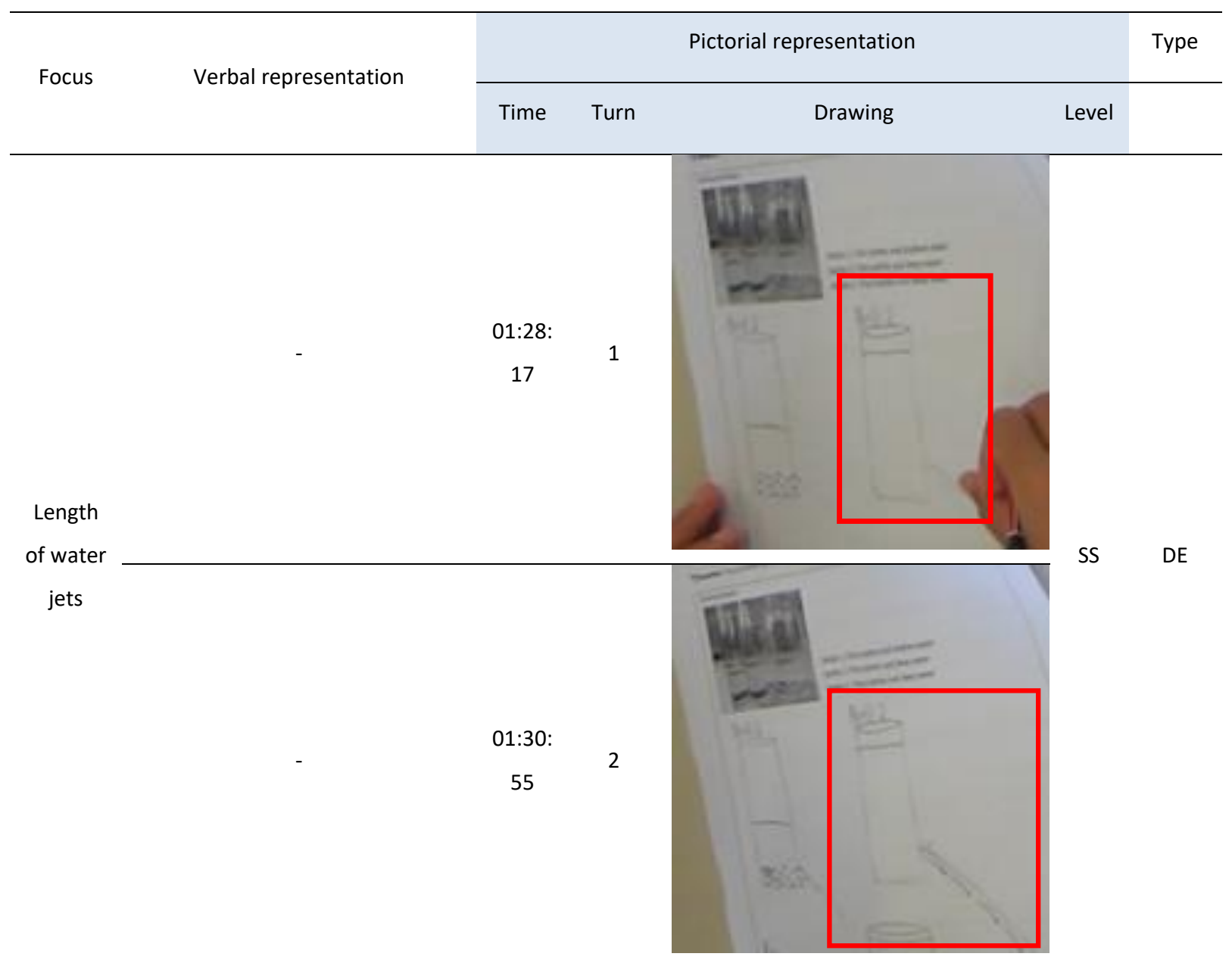

(Group 4, 01:36:41)

$1 \mathrm{R} 2$ : What this means? Oh, pressure

2 G4S3: Yes.

Degree 3 R2: Then, you mean this [dark

of symbol] means more pressure than this [light symbol]?

4 G4S3: Yes. And, the way the darker is the more weight.

5 R2: Aha, when you go deeper, the more weight.

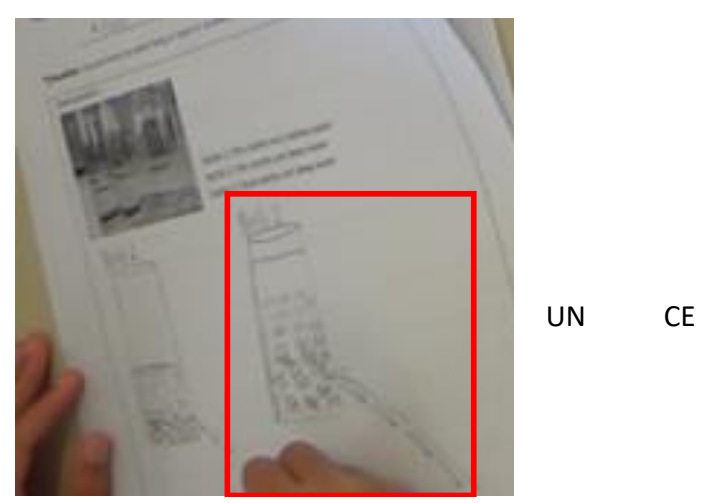

[Drawing his own symbol to represent the degree of water pressure with darkness] 


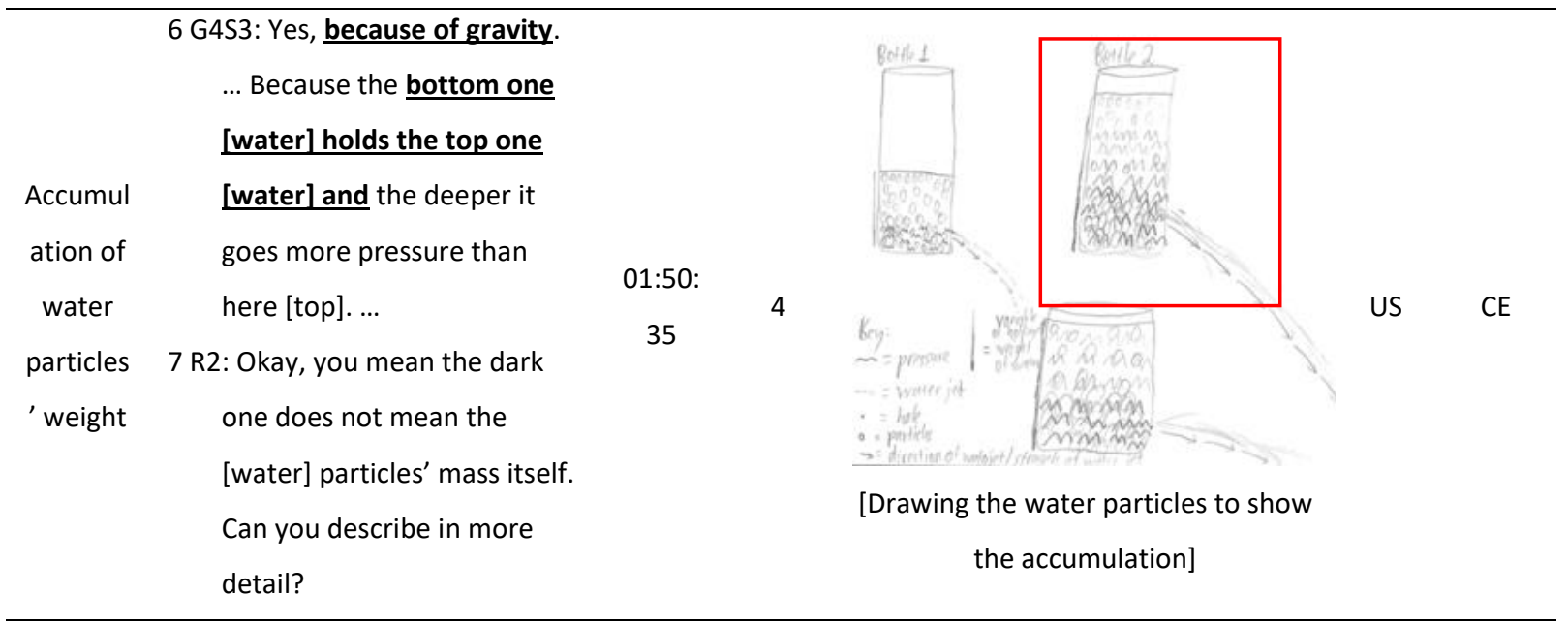

As you swim deeper, how does the water pressure change? Why?

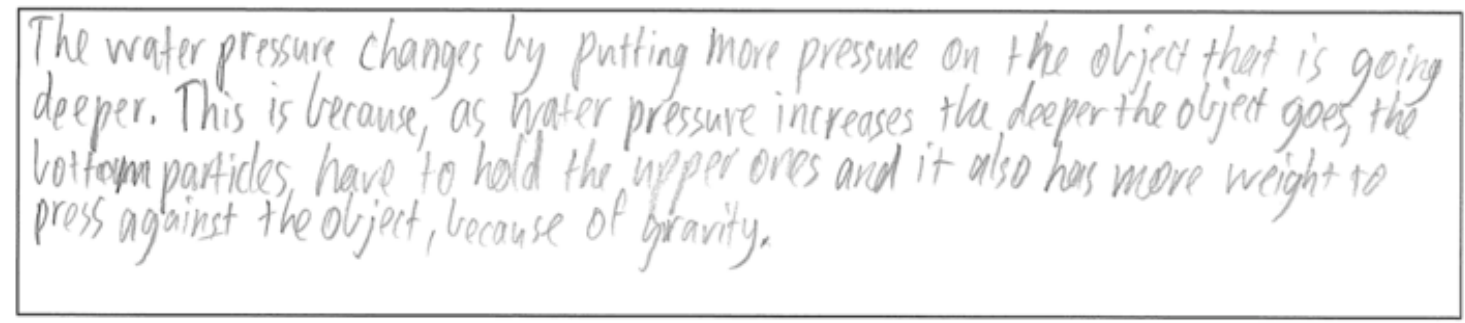

Text: 'The water pressure changes by putting more pressure on the object that is going deeper. This is because, as water pressure increases the deeper the object goes, the bottom particles have to hold to upper ones and it also has more weight to press against the object, because of gravity.'

Figure 6. G4S3's written text about water pressure

\section{Response to research question 2: Roles of three pictorial representational levels in the construction of explanations}

Focusing on a phenomenon at the SS level

Based on our analysis, drawing at the SS level caused most students to focus on the other levels in constructing explanations. A diagram at the SS level as a descriptive explanation represents what students focus on when beginning a drawing. Considering that external representation plays a role as an anchor and structure of cognitive behaviour (Zhang \& Norman, 1994), representing the SS level played a deciding role in helping students focus on the phenomenon in determining the reason why the phenomenon happened. This deliberation 
shaped the subsequent development of different causal explanations from each group illustrating how students made sense of the phenomenon.

The SS level's role in drawing was clearly observed in the first lesson, whose main question was 'If we tilt three bottles, one containing solids, one containing liquids and one containing gases, what happens in each bottle in terms of particles?' In this lesson, two different phenomena were focused by various groups: the position of matter and the shape of matter. Depending on what students focused on, their conceptions were differently represented as either gravity or attraction between molecules. For the initial effort, Groups 1 and 2 focused on the shape of matter and Groups 3 and 4 focused on the position of matter, though both were drawn at the SS level. This focus was revealed in the whole-class discussion (see Table 10). In the final drawing, the different causal explanations depended on the initial focus. Groups 1 and 2 generated an explanation showing the concept of energy and attraction with drawings that were at the US and UN levels, while Groups 3 and 4 constructed an explanation showing the concept of gravity with arrows at the UN level. Group 4 went further and made a deeper explanation to connect both phenomena based on the focus of each SS level. This comparison of the four groups in the first lesson shows that the SS level can be a precursor for constructing explanations. In short, drawing at the SS level focuses the observers' attention on the specific phenomenon in the experiment and can extend students' pondering to help them generate a proper explanation to make sense of it. 
Table 10. Comparison of each group's drawing depending on which phenomenon is being focused on

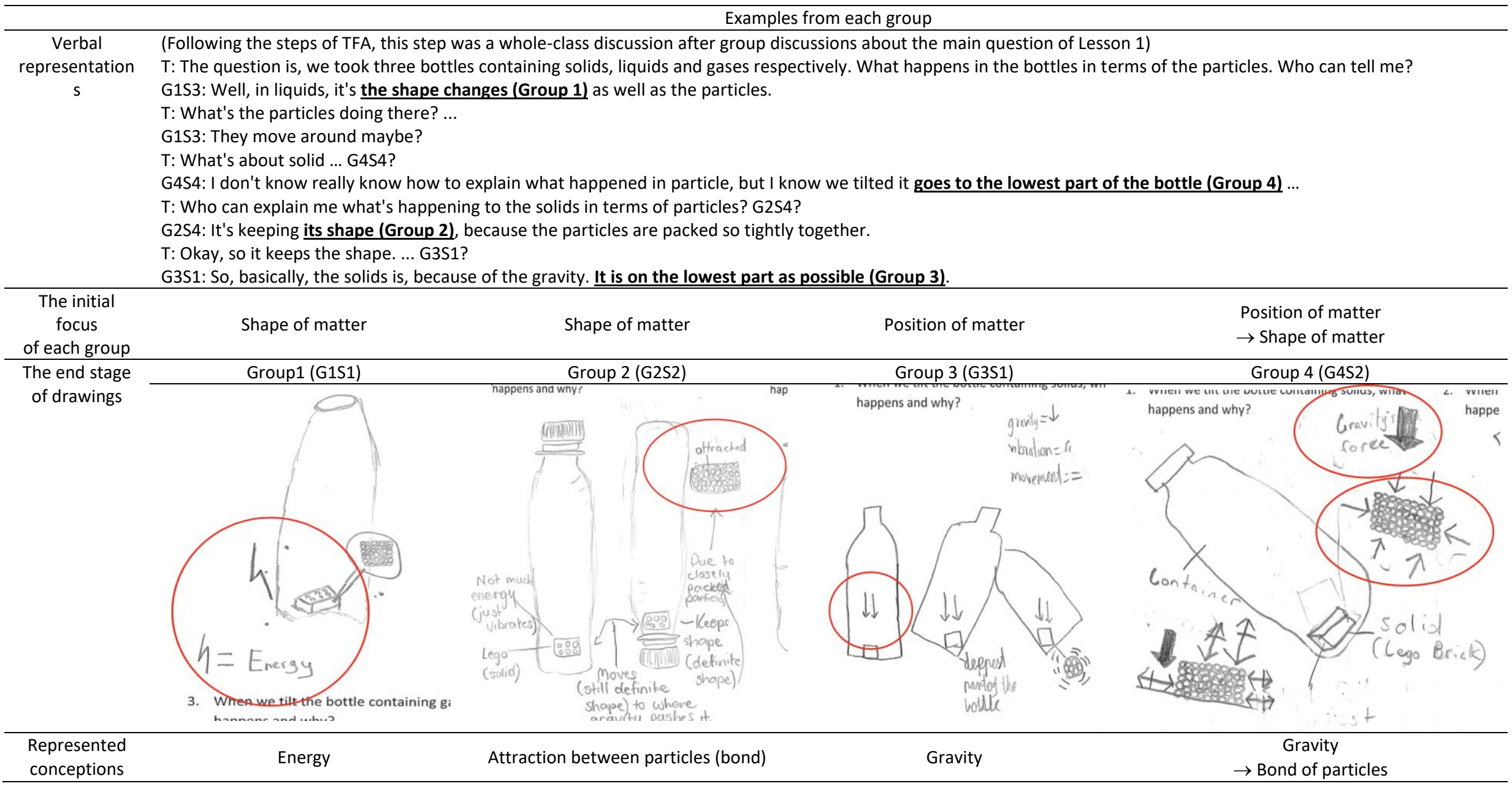


Prompting from making sense of what happened to why it happened by means of the unseen (US and UN) levels

The US and UN levels help students go from making sense of what happened to why it happened, and this development forms the reciprocal relationship among the three levels. In order to make sense of scientific phenomena, students had to make an effort to figure out the phenomena by drawing particles and/or utilising their scientific knowledge. This action allowed students to move from describing a phenomenon to constructing the cause-and-effect relationships involved in the phenomenon.

In some cases, the US level prompted the involvement of the UN level when constructing causal explanations. Students were able to make sense of what happened through drawing the observed phenomena and the particles involved. Drawing the particles allowed the students to see the states or movements of the substances at the SS and US levels. However, a drawing at this level does not show why a phenomenon occurs. To show the mechanism of a phenomenon, students should demonstrate the idea of why the substances are in the state they are in when a phenomenon is occurring. For example, for air pressure concepts, there is a series of ideas related to air pressure between the US and UN levels such as the movement of the air particles, their collisions at a boundary, the pressure they exert and the air pressure. The four ideas in this series can be classified into two parts: descriptive concepts such as air particles and their movement and interpretive concepts such as pressure. The interpretive concepts focus more on how we take and interpret the scientific phenomenon while the descriptive concepts focus on describing the states or movements of the substances. In constructing an explanation, when students draw the particles in relation to the first concept, they should be asked to decide and draw many aspects of particles such as location, direction, shape, speed, path and size. Many aspects of drawing at the US level may trigger making sense of a phenomenon and 
prompt involving the UN level to interpret its mechanism. The following case shows this trigger.
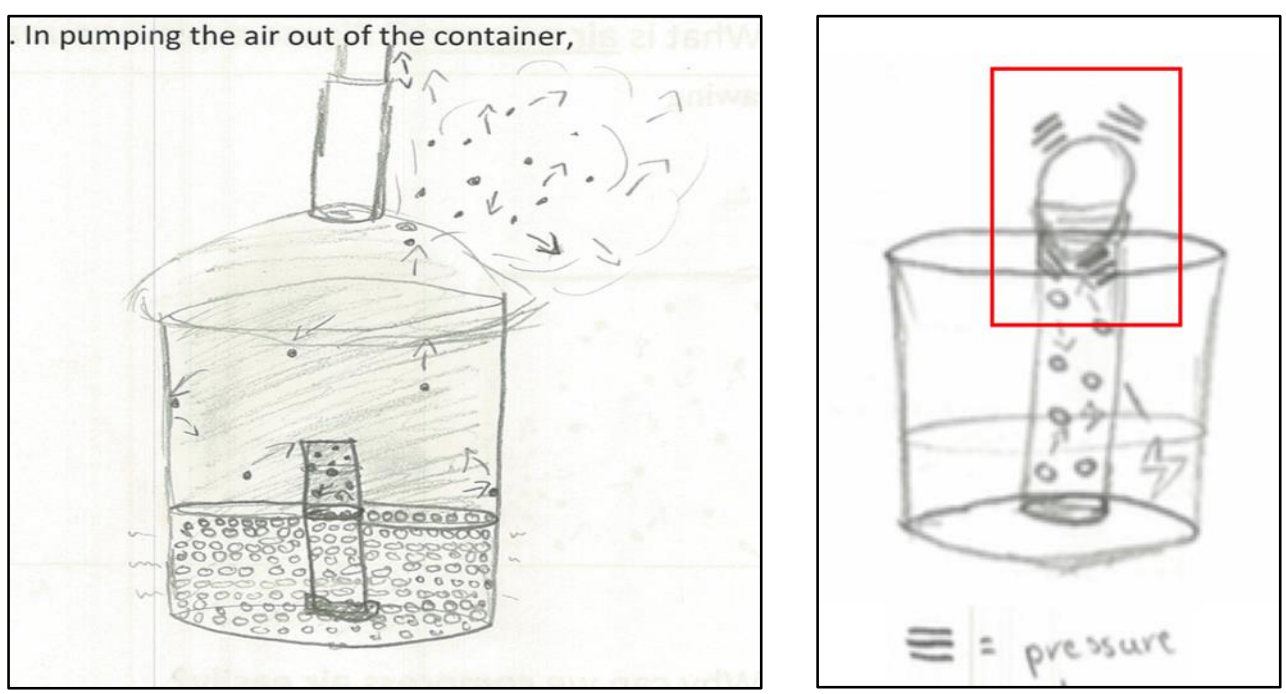

Detailed Explanation in Paragraph (Your answer to the Question)

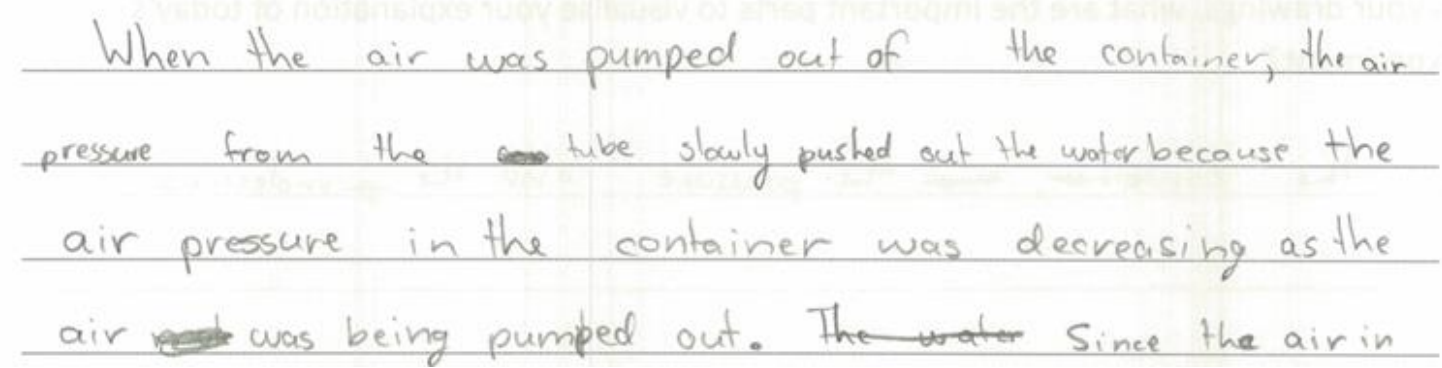

Text: 'When the air was pumped out of the container, the air pressure from the tube slowly pushed out the water because the air pressure in the container was decreasing as the air was being pumped out.'

Figure 7. Comparing G1S4's drawing in Lesson 2 (upper left) and in Lesson 3 (upper right). Although she explained the phenomenon in written text (bottom) using the concept of air pressure in Lesson 2, she eventually created her own symbol to represent the air pressure in Lesson 3.

As shown in Table 8 and in Figure 7, G1S4 was able to create her own symbol to represent air pressure in Lesson 3 while she had not been able to represent this concept in Lesson 2. The main questions in Lesson 2 were "What happened in the water cylinder when the air in the container was decompressed? Why did it happen?' The height of the water in the cylinder (long tube) went down because the air pressure of inside of cylinder was relatively 
larger than the air pressure in the container when the air was pumped out. Even though she understood the concept of air pressure in Lesson 2 and explained the mechanism in the paragraph shown in Figure 7 (bottom), she depicted the phenomenon using only the movement of particles in Lesson 2, as shown in Figure 7 (upper left). Through continuing to create drawings related to the concept of air pressure during the two lessons, she might have involved the concept of air pressure based on her understanding of the relationship between the speed of the air particles and air pressure and finally created her own symbol for air pressure, as shown in Figure 7 (upper right). This understanding may have resulted from the three levels forming meaningful relationships at the sensory level and the unseen levels in constructing causal explanations. Thus, we can infer that drawing the particles at the US level, which prompts involving the UN level, contributes to making sense of why a phenomenon happens.

In essence, the UN level involves the mechanism of the phenomenon. The concept of force, which is at the UN level, is an interaction between substances, thus answering why the substances involved are in a specific state or movement. For example, G3S2, who was following the SS-UN pattern in Lesson 2, made sense of how the water pressure affected the length of the water jetting through by drawing diagrams at the UN level. As shown in Table 7, G3S2 explained why the lengths of the water jets were different through drawing different length arrows that represented the magnitude of the water pressure. In addition, he also depicted why the water pressure in Bottles 2 and 3 is the same through drawing a line that represented the feature of water pressure and clearly answered the researcher's questions. His diagram may not be the result of his first idea but rather the result of his elaboration of representing this mechanism of water pressure. We can therefore infer that drawing diagrams at the UN level prompted students to make sense of the mechanism of the phenomenon.

However, this was not always the case when students just provided a concept on their drawing to describe a phenomenon. For instance, G1S3 drew the water pressure in a simple, descriptive way, but the UN level did not show how the pressure acted on the water (Figure 8, 
left). On the other hand, G4S3 drew the water pressure more precisely, representing the reason within the relationship between the length of the water jets and the water pressure (Figure 8, right). If G1S3 had elaborated his drawing to represent the water pressure in the same way that G4S3 did, he may have been able to construct a causal explanation. From a developmental perspective, involving the UN level can play a role in making sense of why a phenomenon occurs within the other levels. When the interplay of all levels is represented, the levels can form a deeper relationship in an explanation, and each can play a reciprocal role to one another.

In summary, drawing at the US and UN levels prompted students to move from making sense of what happened to explaining why it happened, even though these drawings did not guarantee the involvement of developing mechanisms of phenomena. However, based on continuous efforts to represent the relationships among the different levels of representation, students can be prompted to develop causal explanations of scientific phenomena.
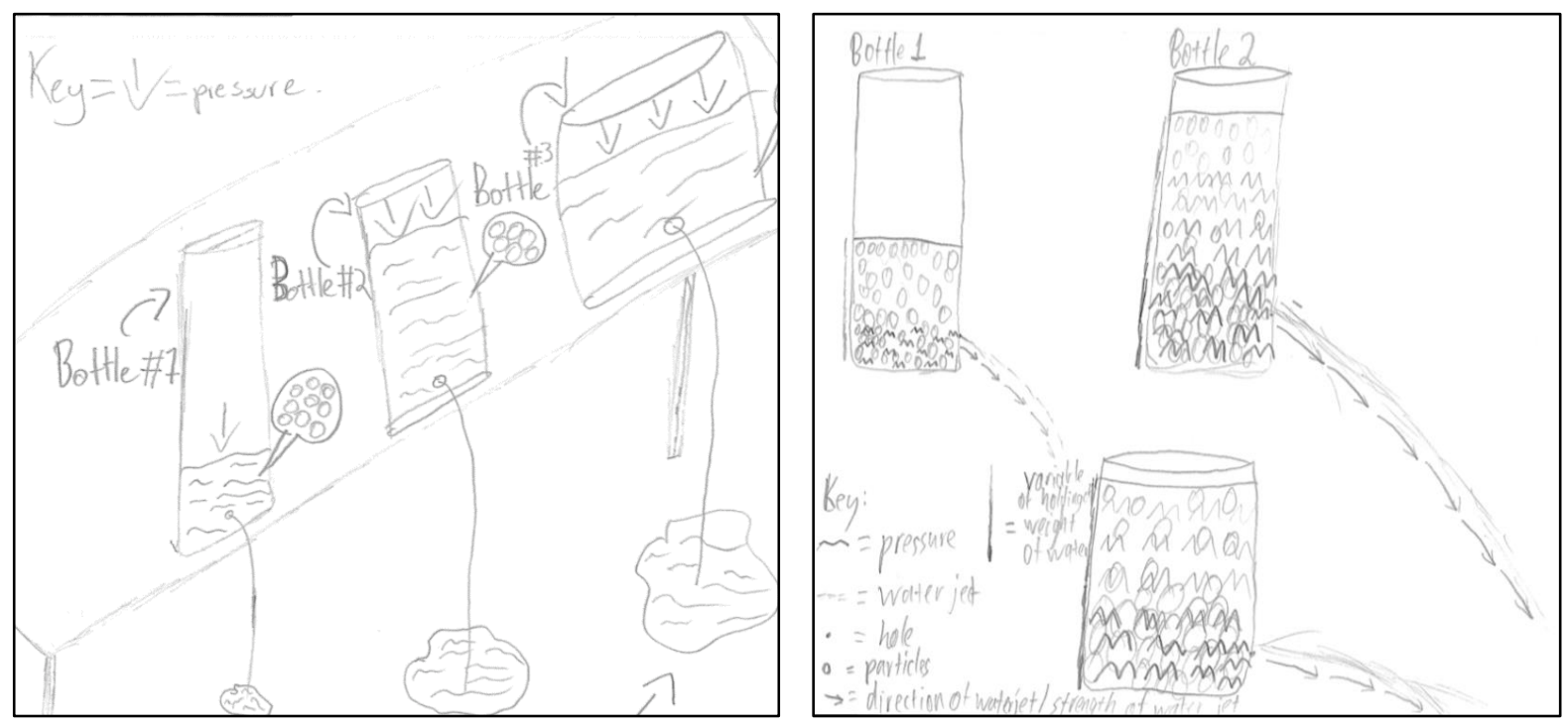

Figure 8. Comparing the G1S3's (left) and G4S3's (right) drawings of water pressure in Lesson 2. It is difficult to find the relationship between water pressure and the length of water jets in left drawings while the right drawings show this relationship. 


\section{Discussions}

To understand the process of student learning through drawing, we investigated the sequential processes of how students constructed scientific explanations of phenomena focusing on the pictorial representation. For this purpose, an analytic framework (Table 3) involving the representational levels (i.e., sensory, unseen substance, and unseen non-substance) was developed by the authors that took into account the features of learning physics concepts in a qualitative way. We found that there were five patterns of interplay in the sequential process of drawing: SS, SS-US, SS-UN, SS-US-UN and SS-UN-US. All students began drawing explanatory diagrams from the SS level as the first step in their drawings based on a phenomenon they initially focused on. They then generated their explanation using the unseen levels through the interplay among different levels. The most common patterns were SS-US and SS-US-UN. In this interplay among levels, the SS level played a key role in building the explanation through making focuses on specific phenomena, and the unseen levels played a decisive role in making sense of the phenomena. In particular, when all three levels formed a meaningful relationship, students were able to provide answers that involved causal explanations for the scientific questions of what happened and why it happened.

Because the important issue when interpreting the results of this study is how the researchers' questions affected the students' development of drawings, the influence of the researchers' questions on the students' behaviours/responses needs to be carefully analysed. Although this intervention affected students' development, it seemed that students' representational sequences did not appear to be directly affected by the researchers' questions. As shown in the SS pattern, students did not draw any air particles even though the teacher and the researchers asked them to think in terms of air particles. In their further development, students also did not immediately draw things that they were asked to draw. Rather, in order to make sense of the phenomenon and then organise and draw their diagrams, they seemed to 
integrate the content that they had discussed with peers, the concepts that they learned, and the questions that were asked by the researchers.

At the same time, this experience of repeated drawing of particles might be one of the crucial factors that affected the sequential pattern of students' drawings. There were many more students who followed the SS-US and the SS-US-UN patterns in Lessons 3, 4 and 5 than followed the SS-UN and the SS-UN-US patterns, as shown in Table 4. This result may show that the experience of drawing particles, which can be a descriptive concept, played a certain role: stimulating students to have a particle view of scientific phenomena in the topics they drew. On the other hand, drawing air pressures and forces, which can be interpretive concepts, seems to have less of an effect on the sequential patterns than drawing air particles. This reason may be related to generating new conventions or symbols for representing concepts at the UN level and/or to developing the elaborated understandings of phenomena. In order to scaffold students to draw diagrams at the UN level, as mentioned in the method section, they may need to be guided with specific and concrete 'why' questions and questions about how concepts can be represented.

Overall, the results of this study indicate that the students' sequential drawing patterns were the outcomes of various instructional efforts, such as doing a hands-on activity, making a verbal explanation and sharing ideas with peers and the teacher, which are related to the steps of the TFA. In addition, across TFAs, various factors affected students' drawings, including questionings and experiences of drawing specific diagrams. Although student-generated drawings involve complex processes, we focus our discussion on implications based on the representational levels. 


\section{Implications}

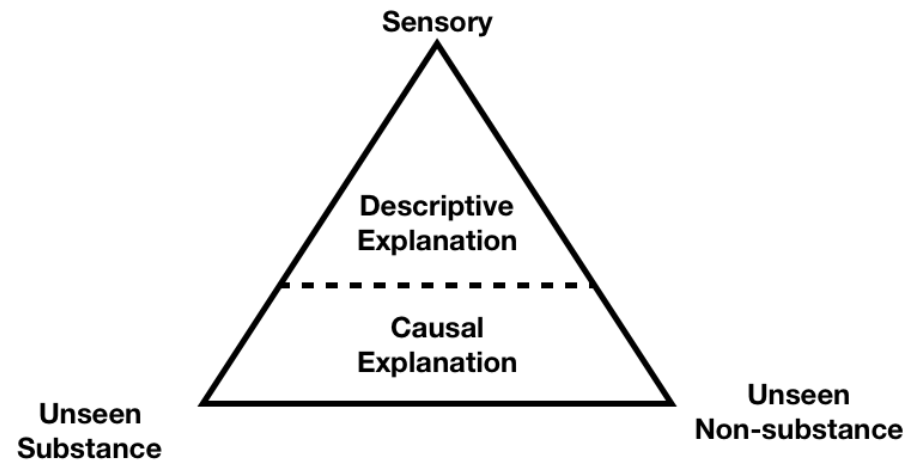

Figure 9. Three levels of pictorial representation within the types of explanation

This study investigated the sequential pattern of students' drawings in terms of representational levels. This investigation suggests an analytic map (Figure 9) that involves representational levels and types of explanations that can be used to diagnose students' drawings and guide them to constructing scientific explanations using drawings when students learn physics concepts in a qualitative way. Integrating these different representational levels is a challenging but crucial issue in students' learning in science classes (Authors, 2009). Our results have shown that one aspect of this integration process is sequential processes of interplay among the different levels of pictorial representation. Thus, the analytic map for understanding students' drawing processes shown in Figure 9 can be used to diagnose their integration processes and guide them to make causal explanations. For example, if students have many difficulties in drawing at the unseen levels, teachers can suggest that students think in terms of particles initially. As discussed above, students may tend to adopt drawing at the US level more easily than at the UN level. If students draw the movement of particles, teachers could suggest that students think about and draw why the particles are in the states. On the other hand, in terms of types of explanation, teachers can continue to ask students to think about the relationship among the three levels of representation. For instance, if students draw 
diagrams such as G1S3's drawings on the left of Figure 8, teachers can provide comments about how the water pressure exactly affects the length of water jet in order to elicit causal explanations such as G4S3's drawings on the right of Figure 8.

Although this analytic map was derived from student-generated drawing, there is a possibility that this map can serve as an assessment tool to capture students' understanding of their various representations. If students verbally explain how an egg on the top of the bottle goes to the inside of the bottle, the egg, movement of air particles around the egg and air pressure will be still used to answer the question. With a perspective that drawings are representations of students' conceptions, students visually reason the mechanism of how the egg goes into the bottle while they verbally explain the question (Ehrlén, 2009). This being so, students' understanding can be revealed through their verbal representation, in terms of pictorial representational levels. In this regard, in science classroom where students are given opportunities to represent their ideas, this analytic map shown in Figure 9 can be used as a general assessment tool to capture students' ongoing understanding on specific topics, in particular, when students learn physics.

In this study, we primarily focused on the sequential patterns in terms of pictorial representational levels. Even though these drawing patterns would be affected by various factors such as students' prior knowledge and experience, pedagogical interventions, and drawing symbols, we think that the results and discussion of this study present a novel situation that provides a clearer understanding of the processes involved in students' drawings. Based on this understanding, in a further study, we intend to investigate those factors that affect the representational levels in order to develop further concrete pedagogical implications to support student-generated representation to improve students' scientific understanding. 


\section{References:}

Authors. (2009).

Authors. (2014).

Authors. (2016).

Authors. (2017).

Ainsworth, S., Prain, V., \& Tytler, R. (2011). Drawing to learn in science. Science, 333(6046), 1096-1097.

Berland, L. K., \& Reiser, B. J. (2009). Making sense of argumentation and explanation. Science Education, 93(1), 26-55.

Braaten, M., \& Windschitl, M. (2011). Working toward a stronger conceptualization of scientific explanation for science education. Science Education, 95(4), 639-669.

Bucat, B., \& Mocerino, M. (2009). Learning at the sub-micro level: Structural representations. In J. K. Gilbert \& D. F. Treagust (Eds.), Multiple representations in chemical education (pp. 11-29). London: Springer.

Ehrlén, K. (2009). Drawings as representations of children's conceptions. International Journal of Science Education, 31(1), 41-57.

Forbes, C., Lange, K., Möller, K., Biggers, M., Laux, M., \& Zangori, L. (2014). Explanationconstruction in fourth-grade classrooms in Germany and the USA: A cross- national comparative video study. International Journal of Science Education, 36(14), 1-24.

Gilbert, J. K., Boulter, C. J., \& Rutherford, M. (2000). Explanations with models in science education. In J. K. Gilbert (Ed), Developing models in science education (pp. 193-208). Dordrecht: Springer.

Gooding, D. C. (2006). From phenomenology to field theory: Faraday's visual reasoning. Perspectives on Science, 14(1), 40-65. 
Hsieh, W. M., \& Tsai, C. C. (2017). Exploring students' conceptions of science learning via drawing: A cross-sectional analysis. International Journal of Science Education, 39(3), 274-298.

Johnstone, A. H. (1982). Macro- and micro-chemistry. School Science Review, 64, 377-379.

Kress, G., Jewitt, C., Ogborn, J., \& Tsatsarelis, C. (2001). Multimodal teaching and learning: The rhetorics of the science classroom. London: Continuum.

Larkin, J., \& Simon, H. (1987). Why a diagram is (sometimes) worth ten thousand words. Cognitive Science, 11(1), 65-100.

Marais, P., \& Jordaan, F. (2000). Are we taking symbolic language for granted? Journal of Chemical Education, 77(10), 1355-3.

Maries, A., \& Singh, C. (2017). Do students benefit from drawing productive diagrams themselves while solving introductory physics problems? The case of two electrostatics problems. European Journal of Physics, 39(1), 015703.

Merriam, S. B. (1998). Qualitative research and case study applications in education. revised and expanded from "Case study research in education.". San Francisco, CA: JosseyBass Publishers.

Newberry, M., \& Gilbert, J. K. (2007). Bringing learners and scientific expertise together. In K. S. Taber (Ed.), Science education for gifted learners (pp. 197-211). London: Routledge.

Prain, V., Tytler, R., \& Peterson, S. (2009). Multiple representation in learning about evaporation. International Journal of Science Education, 31(6), 787-808.

Preston, C. (2016). Effect of a science diagram on primary students' understanding about magnets. Research in Science Education, 46(6), 857-877.

Quillin, K., \& Thomas, S. (2015). Drawing-to-learn: A framework for using drawings to promote model-based reasoning in biology. CBE_Life Sciences Education, 14(1), 116. 
Redish, E. F., \& Kuo, E. (2015). Language of physics, language of math: Disciplinary culture and dynamic epistemology. Science \& Education, 24(5-6), 561-590.

Steffe, L. P. (1991). The constructivist teaching experiment: Illustrations and implications. In E. Glasersfeld (Ed.), Radical constructivism in mathematics education (pp. 177-194). Dordrecht: Springer.

Talanquer, V. (2011). Macro, submicro, and symbolic: the many faces of the chemistry “triplet”. International Journal of Science Education, 33(2), 179-195.

Tippett, C. D. (2016). What recent research on diagrams suggests about learning with rather than learning from visual representations in science. International Journal of Science Education, 38(5), 725-746.

Tytler, R., \& Prain, V. (2010). A framework for re-thinking learning in science from recent cognitive science perspectives. International Journal of Science Education, 32(15), 2055-2078.

Uhden, O., Karam, R., Pietrocola, M., \& Pospiech, G. (2011). Modelling mathematical reasoning in physics education. Science \& Education, 21(4), 485-506.

Van Dijk, T. A. (1981). Episodes as units of discourse analysis. In D. Tannen (Ed.), Analyzing discourse: Text and talk (pp. 177-195). Georgetown: Georgetown University Press.

Van Meter, P. N., \& Garner, J. (2005). The promise and practice of learner-generated drawing: Literature review and synthesis. Educational Psychology Review, 17(4), 285-325.

Yeo, J., \& Gilbert, J. K. (2014). Constructing a scientific explanation: A narrative account. International Journal of Science Education, 36(11), 1902-1935.

Yeo, J., \& Gilbert, J. K. (2017). The role of representations in students' explanations of four phenomena in physics: Dynamics, thermal physics, electromagnetic induction and superposition. In D. F. Treagust., R. Duit., \& Hans. E. Fischer (Eds.), Multiple representations in Physics Education (pp. 255-287). Cham, Switzerland: Springer. 
Zhang, J. (1997). The nature of external representations in problem solving. Cognitive Science, 21(2), 179-217.

Zhang, J., \& Norman, D. A. (1994). Representations in distributed cognitive tasks. Cognitive Science, 18(1), 87-122. 